\title{
Hubungan Gaya Belajar dengan Indeks Prestasi Semester Mahasiswa Prodi DIV Jurusan Kebidanan di Poltekkes Kemenkes Palu
}

\author{
Arie Maineny \\ Prodi D-IV Jurusan Kebidanan, Poltekkes Kemenkes Palu \\ Email Korespondensi: arie.maineny@gmail.com
}

Article Info

Article history:

Submitted: 2019-04-08

Accepted: 2019-05-13

Published: 2019-08-31

Keywords:

learning styles;

Grade Point Average

(GPA);

\section{ABSTRACT}

Every student has a different way of understanding and obtaning information. These differences can be influenced by learning styles. The calculation results based on the Grade Point Avarage (GPA) of the third-grade DIV Midwifery students showed that the GPA in each semester fluctuate, and the result of interviews most students used the method of learning with the rote system. This study was intended to know the correlation between learning styles with the GPA of the students. This study used an analytical survey method with a cross-sectional approach a stratified random sampling technique with 42 respondents, data analysis were done in univariate and bivariate using chi-square test. The results of the statistical test shows that the correlation between learning styles with the GPA was $p$-value 0,459 . The most used learning style by respondents was auditory. The GPA category most owned by respondents was GPA ranges between 2,753,50 which was equal to $90,5 \%$. The conclusion is that there was no correlation between of learning styles with GPA.

\section{ABSTRAK}

Kata Kunci:

Gaya belajar; Indeks Prestasi Semester;
Setiap mahasiswa memiliki cara yang berbeda dalam memahami dan menyerap suatu informasi yang didapatkan, Perbedaan tersebut dapat dipengaruhi oleh gaya belajar. Hasil perhitungan nilai indeks prestasi semester mahasiswa tingkat III Prodi DIV Kebidanan menunjukkan nilai indeks prestasi ditiap semesternya berfluktuasi, dan hasil wawancara kebanyakan mahasiswa menggunakan cara belajar dengan sistem hafalan. Tujuan penelitian ini adalah diketahuinya Hubungan Gaya Belajar dengan Indeks Prestasi Semester. Penelitian ini menggunakan metode survey analitik dengan pendekatan cross sectional, tehnik pengambilan sampel stratified random sampling dengan jumlah responden sebanyak 42 responden, analisis data dilakukan secara univariat dan bivariat menggunakan uji statistik chi square. Hasil uji statistik menunjukkan bahwa hubungan gaya belajar dengan indeks prestasi semester diperoleh nilai $p=0.459$. Gaya belajar paling banyak digunakan oleh responden adalah gaya belajar auditorial. Kategori indeks prestasi semester paling banyak dimiliki oleh responden adalah indeks prestasi yang berkisar antara 2.75-3.50 yaitu sebesar 90,5\%. Kesimpulan tidak terdapat hubungan gaya belajar dengan indeks prestasi semester. 


\section{PENDAHULUAN}

Pendidikan yang berkualitas merupakan faktor utama yang sangat penting dalam usaha untuk menciptakan SDM yang berkualitas. Universitas merupakan salah satu lembaga yang menyelengarakan pendidikan formal. Universitas memiliki peranan yang sangat penting dalam mewujudkan tujuan pendidikan nasional melalui proses belajar mengajar. Keseluruhan upaya pendidikan, proses belajar merupakan aktivitas yang paling penting, karena melalui proses itulah tujuan pendidikan akan dicapai dalam bentuk perubahan perilaku atau pribadi mahasiswa. ${ }^{1}$

Penyelenggaraan pendidikan Diploma IV kebidanan mengacu pada standar nasional pendidikan, dimana beban studi program Diploma IV sekurang-kurangnya adalah 144 SKS dan sebanyak-banyaknya 160 SKS yang dijadwalkan untuk 8 semester (Kepmendiknas Nomor 232/U/2000) yang terdiri dari $40 \%$ teori, $60 \%$ praktikum dan klinik. ${ }^{2}$

Proses belajar terjadi melalui banyak cara baik disengaja maupun tidak disengaja yang berlangsung sepanjang waktu dan menuju pada suatu perubahan pada diri pembelajar. Proses belajar itu akan diperoleh hasil belajar yang berbedabeda setiap mahasiswa. Faktor yang dapat mempengaruhi perbedaan hasil belajar setiap mahasiswa adalah faktor internal, faktor eksternal dan faktor pendekatan belajar salah satunya gaya belajar. ${ }^{3,4}$

Gaya belajar dibedakan menjadi tiga yaitu: gaya belajar visual adalah gaya belajar dengan cara melihat, mengamati, memandang dan sejenisnya. Kekuatan gaya belajar ini terletak pada indera penglihatan. Gaya belajar auditorial adalah gaya belajar dengan cara mendengar. Seseorang dengan gaya belajar ini lebih dominan dalam menggunakan indera pendengaran untuk melakukan aktivitas belajar. Gaya belajar kinestik adalah gaya belajar dengan cara bergerak, bekerja dan menyentuh. Maksudnya ialah belajar dengan mengutamakan indera perasa dan gerakan-gerakan fisik. ${ }^{5}$

Penelitian yang pernah dilakukan oleh Wulandari (2011) di Prodi DIV Kebidanan Universitas Sebelas Maret Surakarta didapatkan hasil bahwa terdapat 25 mahasiswa $(43,1 \%)$ yang memiliki gaya belajar visual: 19 mahasiswa $(32,8 \%)$ dengan indeks prestasi 27,5-3,50 dan 6 mahasiswa (10,3\%) dengan indeks prestasi 2,00-2,75. Gaya belajar auditorial menempati urutan kedua dengan jumlah 13 mahasiswa (22,4\%): 9 mahasiswa (15,5\%) dengan indeks prestasi 2,75-3,50 dan 4 mahasiswa $(6,9 \%)$ dengan indeks prestasi $2,00-2,75$. Selanjutnya gaya belajar kinestik dimiliki oleh 8 mahasiswa (13,8\%): 6 mahasiswa (10,3\%) dengan indeks prestasi $2,75-3,50$ dan 2 mahasiwa $(3,4 \%)$ dengan indeks prestasi 2,00-2,75. Gaya belajar visual-auditorial 4 mahasiswa $(6,9 \%)$ dengan indeks prestasi $2,75-3,50$, gaya belajar visual-kinestik: 2 mahasiswa (3,4\%) dengan indeks prestasi 2,00-2,74 dan 2 mahasiswa $(3,4 \%)$ dengan indeks prestasi $2,75-3,500$. Dan terakhir adalah gaya belajar auditorial kinestik ada 4 mahasiswa $(6,9 \%)$ dengan indeks prestasi 2,75-3,50. Hasil penelitian didapatkan bahwa ada hubungan gaya belajar dengan prestasi belajar mahasiswa, dimana gaya belajar didominasi oleh gaya belajar visual. ${ }^{6}$

Penelitian Rahmawati (2016) di Fakultas Kedokteran Universtias Lampung, dalam penelitiannya didapatkan hasil bahwa terdapat hubungan antara gaya belajar dengan indeks prestasi kumulatif mahasiswa Fakultas Kedokteran Lampung. Penelitian ini mengemukakan bahwa gaya belajar kinestik $(47,9 \%)$ dominan digunakan oleh mahasiswa dibanding gaya belajar lainnya. Penelitian tersebut mengemukakan bahwa semakin tinggi penggunaan gaya belajar secara tepat maka akan meningkatkan prestasi belajar mahasiswa. ${ }^{7}$ 
Berdasarkan data dari Sub Unit Akademik Prodi DIV Kebidanan Poltekkes Kemenkes Palu (2017) didapatkan rata-rata indeks prestasi setiap semester mahasiswa tingkat III Prodi DIV Kebidanan yang berjumlah 43 mahasiswa adalah: semester I terdapat 34 mahasiswa (79,06\%) memiliki indeks prestasi 3,51-4,00 dan 9 mahasiswa (20,93\%) memiliki indeks prestasi 2,75-3,50. Semester II terdapat 14 mahasiswa (32,5\%) memiliki indeks prestasi 3,51-4,00, 28 mahasiswa $(65,11 \%)$ memiliki indeks prestasi 2,75-3,50 dan 1 mahasiswa (2,32\%) memiliki indeks prestasi $0,00-0,99$. Semester III semua mahasiswa memiliki indeks prestasi $2,75-3,50$ berjumlah 43 mahasiswa (100\%). Semester IV terdapat 2 mahasiswa $(4,65 \%)$ memiliki indeks prestasi 3,51-4,00, 40 mahasiswa (93,02\%) memiliki indeks prestasi 2,75-3,50 dan 1 mahasiswa (2,32\%) memiliki indeks prestasi 2,00-2,74. Hasil tersebut menunjukkan bahwa nilai indeks prestasi ditiap semesternya belum mengalami peningkatan secara signifikan.

Hasil wawancara dengan beberapa mahasiswa Poltekkes Kemenkes Palu Jurusan Kebidanan pada tanggal 23 Januari 2018 yaitu mahasiswa menggunakan metode belajar menghafal sebelum ujian karena tidak bisa mengingat pelajaran yang diberikan dahulu tanpa menghafal. menghafal hanya biasa diingat untuk sementara bila tanpa diimbangi dengan pemahaman pada suatu materi. Oleh karena itu mahasiswa perlu mengenali gaya belajar secara efektif agar bisa memaksimalkan waktu belajar untuk memperoleh hasil belajar yang baik. Mahasiswa yang sudah bisa mengetahui gaya belajarnya tinggal menentukan langkah dan cara yang tepat memaksimalkan waktu belajar untuk mendapat prestasi yang baik. Tujuan penelitian ini adalah untuk melihat hubungan Gaya belajar dengan Indeks Prestasi Semester Mahasiswa Jurusan Kebidanan Prodi DIV Kebidanan di Poltekkes Kemenkes Palu.

\section{METODE PENELITIAN}

Jenis penelitian yang digunakan adalah penelitian analitik dengan pendekatan cross sectional yaitu suatu penelitian untuk mempelajari hubungan antara gaya belajar mahasiswa terhadap indeks prestasi semester, dengan menggunakan data primer yaitu pengisian kuesioner gaya belajar oleh mahasiswa tingkat III Prodi DIV Kebidanan Poltekkes Palu. Populasi target dari penelitian ini adalah mahasiswa Poltekkes Kemenkes Palu Tahun ajaran 2017/2018. Populasi terjangkau dari penelitian ini adalah mahasiswa Jurusan Kebidanan Prodi DIV Kebidanan Poltekkes Kemenkes Palu. Sampel dalam penelitian ini adalah seluruh mahasiswa tingkat III Prodi DIV Kebidanan Poltekkes Kemenkes Palu yang berjumlah 43 mahasiswa namun selama proses penelitian berlangsung, ada 1 orang mahasiswa tidak pernah hadir dalam mengikuti perkuliahan sehingga besar sampel dalam penelitian ini menjadi 42 responden. Teknik pengambilan sampel dalam penelitian ini menggunakan teknik stratified random sampling yaitu metode pengambilan sampel acak berstrata berdasarkan tingkatan tertentu. Penelitian dilaksanakan di Poltekkes Kemenkes Palu Jurusan Kebidanan Prodi DIV Kebidanan pada tanggal 17 Mei 2018 sampai dengan tanggal 2 Juni 2018. Penelitian ini menggunakan alat pengambilan data berupa kuesioner, dan data yang diperoleh dari bagian Akademik Prodi DIV Kebidanan Poltekkes Kemenkes Palu. Metode yang digunakan untuk mengetahui hubungan antara gaya belajar dengan indeks prestasi. Analisis ini menggunakan komputerisasi dengan uji statistik chi square $\left(\mathrm{x}^{2}\right)$ 


\section{HASIL PENELITIAN}

Setelah data penelitian dianalisis maka diperoleh hasil sebagai berikut:

1. Analisis univariat

Tabel 1: Distribusi Indeks Prestasi Semester V Mahasiswa Tingkat III Prodi DIV Kebidanan di Poltekkes Kemenkes Palu

\begin{tabular}{ccc}
\hline Indeks Prestasi & Frekuensi (n) & Presentase (\%) \\
\hline Nilai A $(3,51-4,00)$ & 4 & 9,5 \\
Nilai B $(2,75-3,50)$ & 38 & 90,5 \\
\hline Total & 42 & 100,0
\end{tabular}

Sumber: Data primer, 2018

Tabel.1 menunjukkan bahwa lebih banyak mahasiswa yang memiliki indeks prestasi dengan nilai B yaitu 38 responden (90,5\%) dibandingkan dengan mahasiswa yang memiliki indeks prestasi dengan nilai $A$ yaitu 4 responden $(9,5 \%)$

\begin{tabular}{lcc}
$\begin{array}{l}\text { Tabel 2: Distribusi Gaya Belajar Mahasiswa Tingkat III Prodi } \\
\text { Poltekkes Kemenkes Palu }\end{array}$ & DIV Kebidanan \\
\hline Gaya Belajar & Frekuensi (n) & Presentase (\%) \\
\hline Visual & 15 & 35.7 \\
Auditorial & 16 & 38.1 \\
Kinestik & 6 & 14.3 \\
Visual Auditorial & 3 & 7.1 \\
Visual Kinestik & 2 & 4.8 \\
\hline Total & 42 & 100,0 \\
\hline
\end{tabular}

Sumber: Data primer, 2018

Tabel.2 menunjukkan bahwa gaya belajar yang paling banyak dimiliki oleh mahasiswa tingkat III adalah gaya belajar auditorial sebanyak 16 responden (38.1\%), dan gaya belajar yang paling sedikit dimiliki oleh mahasiswa tingkat III adalah gaya belajar visual kinestik sebanyak 2 responden (4.8\%).

2. Analisis Bivariat

Tabel 3: Distribusi Hubungan Gaya Belajar dengan Indeks Prestasi Semester Mahasiswa Jurusan Kebidanan Prodi DIV Kebidanan di Poltekkes Kemenkes Palu

\begin{tabular}{lccccc}
\hline \multirow{2}{*}{ Gaya Belajar } & \multicolumn{3}{c}{ Indeks Prestasi Semester } & \multirow{2}{*}{ Nilai A } & \multicolumn{2}{c}{ Nilai B } & \multirow{2}{*}{ Nilai p } \\
\cline { 2 - 5 } & $\mathbf{f}$ & $\%$ & $\mathbf{f}$ & $\%$ & \\
\hline Visual & 1 & 6,7 & 14 & 93,3 & \\
Auditorial & 3 & 18,8 & 13 & 13 & \\
Kinestik & 0 & 0 & 6 & 100 & \multirow{2}{*}{0,459} \\
Visual-Auditorial & 0 & 0 & 3 & 100 & \\
Visual-Kinestik & 0 & 0 & 2 & 100 & \\
\hline
\end{tabular}

Sumber : Data primer, 2018

\section{Gaya Belajar Visual}

Responden dengan gaya belajar visual memiliki nilai $A$ sebanyak 1 responden $(6,7 \%)$, dan nilai B sebanyak 14 responden $(93,3 \%)$ 


\section{Gaya Belajar Auditorial}

Responden dengan gaya belajar Auditorial memiliki nilai A sebanyak 3 responden (18,8\%), dan nilai B sebanyak 13 responden (13\%)

\section{Gaya Belajar Kinestik}

Responden dengan gaya belajar Kinsetik tidak ada yang memiliki nilai $A(0 \%)$, dan nilai B sebanyak 6 responden (100\%)

\section{Gaya Belajar Visual-Auditorial}

Responden dengan gaya belajar visual-Auditorial tidak ada yang memiliki nilai A (0\%), dan nilai B sebanyak 3 responden (100\%)

\section{Gaya Belajar Visual-Kinestik}

Responden dengan gaya belajar visual-Auditorial tidak ada yang memiliki nilai A $(0 \%)$, dan nilai B sebanyak 2 responden (100\%)

\section{PEMBAHASAN}

Hasil analisis bivariat antara variabel gaya belajar dengan variabel indeks prestasi semester mahasiswa menunjukkan bahwa responden dengan gaya belajar auditorial memiliki nilai $A$ terbanyak yaitu 3 responden (18.8\%), dan responden dengan gaya belajar visual memiliki nilai B terbanyak yaitu 14 respoden $(93.3 \%)$. Hasil uji chi square dengan menggunakan $\alpha=0.05$ nilai $p$ value: 0.459 ( $p$ value>0.05). sehingga dapat ditarik kesimpulan bahwa tidak ada hubungan antara gaya belajar dengan indeks prestasi semester mahasiswa Jurusan Kebidanan Prodi DIV Kebidanan di Poltekkes Kemenkes Palu.

Menurut analisis peneliti dari hasil bivariat diperoleh mahasiswa yang memiliki gaya belajar auditorial memiliki nilai A terbanyak sedangkan mahasiswa yang memiliki gaya belajar visual memiliki nilai B terbanyak sehingga dapat disimpulkan bahwa mahasiswa akan memperoleh prestasi yang maksimal jika menggunakan gaya belajar auditorial. Menurut asumsi peneliti kebanyakan mahasiswa mendapatkan indeks prestasi dengan nilai $B$ karena mahasiswa hanya menggunakan satu tipe gaya belajar, untuk itu akan lebih efektif jika mahasiswa menggunakan gabungan semua tipe gaya belajar karena dalam pembelajaran kebidanan akan lebih baik jika melihat langsung prosedur kerja, mendengar penjelasan dosen dan melakukan praktik secara mandiri. Tipe gaya belajar setiap mahasiswa berbeda-beda sehingga dalam kegiatan belajar mengajar tenaga pendidik harus memahami perbedaan individu, menciptakan iklim yang kondusif dalam kelas serta menentukan strategi dan metode pembelajaran yang mencakup tipe-tipe gaya belajar misalnya menampilkan gambar, grafik, peta, video materi pelajaran dan langsung mempraktikkan teori yang telah selesai dibahas.

Menurut teori yang dikemukakan oleh Subini (2011) Gaya belajar masingmasing orang berbeda, sebagian orang mungkin lebih dominan menggunakan gaya belajar tertentu dalam segala situasi, namun sebagian yang lain menggunakan cara berbeda untuk situasi yang berlainan. Bagaimanapun gaya belajar yang diterapkan, kita harus dapat menyerap apa yang dipelajari secara optimal. Untuk itu, penting sekali mengenali tipe gaya belajar karena itu dapat membantu dan menentukan keberhasilannya kelak. ${ }^{8}$

Hasil penelitian ini sejalan dengan penelitian yang telah dilakukan oleh Hardiansyah yang berjudul pengaruh gaya belajar terhadap prestasi belajar akademik mahasiswa Fakultas Kedokteran Universitas Diponegoro, hasil analisis menunjukkan tidak ada pengaruh gaya belajar terhadap prestasi belajar akademik mahasiswa Fakultas Kedokteran Universitas Diponegoro. Gaya belajar tertentu yang 
menggabungkan dua model gaya belajar misalnya visual kenestik dapat meningkatkan prestasi belajar mahasiswa. ${ }^{9}$

Keterbatasan dan kelemahan dalam penelitian ini disebabkan karena peneliti tidak meneliti secara bersamaan faktor-faktor lain yang mempengaruhi prestasi belajar mahasiswa, misalnya tingkat intelegensi, sikap, bakat, minat, motivasi lingkungan sosial dan non sosial

\section{SIMPULAN DAN SARAN}

Hasil penelitian ini menyimpulkan bahwa tidak ada hubungan gaya belajar dengan Indeks Prestasi Semester Mahasiswa Penelitian ini diharapkan dapat memberikan masukan bagi institusi khususnya dosen Poltekkes Palu agar dapat membantu mahasiswa mempermudah menerima informasi dalam kegiatan belajar mengajar dengan memahami perbedaan individu, menciptakan iklim yang kondusif dalam kelas serta menentukan strategi pembelajaran inkuiri sosial yang merupakan rangkaian kegiatan belajar dengan melibatkan secara maksimal seluruh kemampuan mahasiswa untuk mencari dan menyelidiki secara sistematis, kritis, logis, analitis dengan metode eksperimen, tugas atau resitasi, latihan dan karya wisata. Mahasiswa dapat menggunakan gaya belajar gabungan dari semua tipe gaya belajar agar dapat memaksimalkan hasil belajar dan prestasi yang diperoleh. Bagi peneliti selanjutnya dapat melakukan penelitian lebih lanjut mengenai hubungan gaya belajar dengan indeks prestasi menggunakan jumlah sampel yang lebih besar dan melihat indeks prestasi kumulatif serta perlu dilakukan penelitian terhadap faktor-faktor lainnya yang dapat mempengaruhi indeks prestasi

\section{DAFTAR PUSTAKA}

1. Baharuddin H, Wahyuni NE. Teori Belajar dan Pembelajaran. Yogyakarta: Ar-Ruzz media; 2015.

2. Kementerian Kesehatan R.I. Kurikulum Inti Diploma IV Kebidanan. Jakarta: Badan pengembangan dan Pemberdayaan SDM Kesehatan; 2014.

3. Abbas Pourhossein Gilakjani, Ahmadi SM. The Effect of Visual, Auditory, and Kinaesthetic Learning Styles on Language Teaching. In: International Conferences on Social Science and Huminity. 2011. hal. 469-72.

4. Syofyan R, Siwi MK. The Impact of Visual, Auditory, and Kinesthetic Learning Styles on Economics Education Teaching. In: 1st International Conference On Economics Education, Economics, Business and Management, Accounting and Entrepreneurship. 2018. hal. 642-9.

5. Porter B, Hernacki M. Quantum Learning: Membiasakan Belajar Nyaman dan Menyenangkan. Bandung: Kaifa; 2014.

6. Wulandari R. Hubungan Gaya Belajar dengan Prestasi Belajar Mahasiswa Prodi DIV Kebidanan. [Surakarta]: Prodi DIV Kebidanan Universitas Sebelas Maret; 2011.

7. Rahmawati E. Hubungan Gaya Belajar dengan Pencapaian Indeks Prestasi Kumulatif Mahasiswa Fakultas Kedokteran. [Lampung]: Fakultas Kedokteran Universitas Lampung; 2016.

8. Subini R. Mengatasi Kesulitan Belajar pada Anak. Jogjakarta: Javalitera; 2017.

9. Hardiansyah. Pengaruh Gaya Belajar terhadap Prestasi Belajar Akademik Mahasiswa Fakultas Kedokteran Universitas Diponegoro. [Semarang]: Fakultas Kedokteran Universitas Diponegoro; 2014. 